American Journal of Applied Sciences 7 (6): 739-745, 2010

ISSN 1546-9239

(C) 2010Science Publications

\title{
Mechanism of Microencapsulation with Urea-Formaldehyde Polymer
}

\author{
Rochmadi, Agus Prasetya and Wahyu Hasokowati \\ Department of Chemical Engineering, Faculty of Engineering, \\ Gadjah Mada University, Bulaksumur Yogyakarta-55284, Indonesia
}

\begin{abstract}
Problem statement: Microcapsule is one of important fine chemical products in the current chemical industries. Better understanding of microencapsulation process is useful to properly design of microcapsule with specific characteristics. The aim of this research is to study the mechanism of UreaFormaldehyde (UF) microcapsules formation. Approach: Microcapsule was prepared in two steps. The first step was the preparation of oil in water emulsion, which was carried out by mixing of UF prepolymer solution with refined palm oil at $50-70^{\circ} \mathrm{C}$, using high speed homogenizer. The second step was microcapsule shell formation, where the $\mathrm{pH}$ of emulsion was adjusted to 3 and the process was run for 3-6 h. At the end of the process, the microcapsule product was cooled with ice and distilled water, filtered, washed and finally dried at $40^{\circ} \mathrm{C}$ under vacuum condition. The diameter and size distribution of the microcapsule product was measured using optical microscope. Results: Microcapsule with the diameter of 20-220 $\mu \mathrm{m}$, together with UF micro particles. Conclusion: UF polymerization reaction took place simultaneously in the solution and at the microcapsule surface. UF reaction in the solution produced UF polymer micro particles, while UF reaction at the microcapsule surface forms microcapsule shell. The UF polymer micro particles precipitated in the form of fine powder, attach to the microcapsule shell. Higher microencapsulation temperature reduced the amount of microcapsule product and increased the amount of micro particles. The microcapsule diameter distribution shifts to smaller diameter and the average diameter $\mathrm{D}_{\text {avg }}$ tends to decrease as the homogenization and microencapsulation time increase. Based on oil and resin efficiencies as well as microcapsule characteristics, the process is best conducted at $50^{\circ} \mathrm{C}, 30 \mathrm{~min}$ of homogenization and $3 \mathrm{~h}$ of microencapsulation time.
\end{abstract}

Key words: Urea-formaldehyde, pre-polymer, microencapsulation, controlled release, micro particle, homogenization

\section{INTRODUCTION}

Microencapsulation has been widely applied in various areas such as pharmaceutical industry, fragrance, perfumery, coating as well as pesticides. One of the microcapsule applications is to enclave active chemical solution, in which this active compound can be slowly released through the shell of microcapsules. This is commonly known as controlled release, as the rate of release can be controlled by selecting the material and thickness of the microcapsule shell.

Various method of microencapsulation have been well known in chemical industry, generally are still in state of the art. Numerous researches have described microencapsulation qualitatively, but only few have been concerned with quantitative description of microencapsulation process, such as the effect of process variables upon the size of microcapsules.
Hence, better understanding of microencapsulation process can help proper design of microcapsule with specific characteristics.

The purpose of this research is to study the mechanism of urea-formaldehyde microcapsules formation, including the effect of some variables upon the characteristics of microcapsules. In this research, palm oil is encapsulated with urea-formaldehyde resin. The main goal of this research is microencapsulation of pesticide solution, with vegetable oil as a solvent.

Mayya et al. (2003) have encapsulated paraffin oil with gelatin and Arabic gum by complex coacervation. Dibutyltin dilaurate as a catalyst of EVA crosslinking in ester-silane exchange reaction has been encapsulated with polycarbonate (Deyrail et al., 2004). Smart method of microencapsulation has been described by Sukhorukov et al. (2005) by selection of material and properties condition. Brown et al. (2003) have

Corresponding Author: Rochmadi, Department of Chemical Engineering, Faculty of Engineering, Gadjah Mada University, Yogyakarta, Indonesia 
encapsulated dicyclopentadiene by in situ polymerization of urea-formaldehyde. Salaun and Vroman (2008) have investigated the effect of core material upon thermal properties of melamineformaldehyde microcapsules. Multilayer of microcapsule shell formation has been described by Radtchenko et al. (2002) as well as Antipov and Sukhorukov (2004). Sun and Zhang (2002) studied the mechanical strength of microcapsules in which the wall was made of melamine-formaldehyde resin, ureaformaldehyde resin and gelatin-Arabic gum. Yin et al. (2007) have encapsulated epoxy with ureaformaldehyde resin for self-healing epoxy composites. Yang and Pan (1996) have patented the method to microencapsulate pesticide solution with ureaformaldehyde resin.

Encapsulation method applied in this research is in situ polymerization of urea-formaldehyde under low $\mathrm{pH}$ (acidic condition). There are 2 steps of process during microcapsule formation. The first step is emulsion of palm oil (vegetable oil) in urea-formaldehyde resin solution, in which palm oil is as a dispersed phase. High rotation speed of stirring is conducted to emulsify palm oil. In this case, high rotation speed homogenizer is used as a stirrer. The second step is microcapsule shell formation. In this step, the $\mathrm{pH}$ of emulsion liquid is adjusted into acidic condition. This promotes the reaction of urea with formaldehyde in the interface of emulsion bubbles, producing a film of ureaformaldehyde polymer as a microcapsule shell.

Two reactions take place when urea reacts with formaldehyde, i.e., addition and condensation:

$$
\begin{aligned}
& \mathrm{H}_{2 \mathrm{~N}}-\mathrm{CO}-\mathrm{NH}_{2}+\mathrm{CH}_{2} \mathrm{O} \rightarrow \mathrm{H}_{2} \mathrm{~N}-\mathrm{CO}-\mathrm{NH}-\mathrm{CH}_{2} \mathrm{OH} \\
& \text { (mono methylol urea) }
\end{aligned}
$$

$$
\mathrm{H}_{2} \mathrm{~N}-\mathrm{CO}-\mathrm{NH}-\mathrm{CH}_{2} \mathrm{OH}+\mathrm{H}_{2} \mathrm{~N}-\mathrm{CO}-\mathrm{NH}-\mathrm{CH} 2 \mathrm{OH} \rightarrow
$$$$
\mathrm{H}_{2} \mathrm{~N}-\mathrm{CO}-\mathrm{NH}-\mathrm{CH}-\mathrm{HN}-\mathrm{CO}-\mathrm{NH}-\mathrm{CH}_{2} \mathrm{OH}+\mathrm{H} 2 \mathrm{O}
$$

Reaction (1) is an addition reaction, where formaldehyde reacts with $\mathrm{H}$ of amine to form methylol. Condensation occurs between $\mathrm{OH}$ of methylol and $\mathrm{H}$ of amine, forming methylene link between amines of 2 urea molecules, as shown in Eq. 2. This condensation reaction results in urea-formaldehyde polymer chain. Addition and condensation reactions are catalyzed either by $\mathrm{OH}^{-}$or $\mathrm{H}^{+}$. The rate of addition reaction in basic condition is as high as the rate in acidic condition. However, the rate of condensation reaction is much faster in acidic condition, compared with that in basic condition. As urea has four $\mathrm{H}$ atoms in amines, it is most possible to produce crosslink or network polymer during condensation reaction. This network polymer is good for microcapsule shell due to its high strength, in which microcapsule is not easy to break up during its application.

\section{MATERIALS AND METHODS}

The experiment of microencapsulation consists of urea-formaldehyde pre-polymer preparation and microencapsulation process. Pre-polymer UreaFormaldehyde (UF) resin was prepared under basic condition $(\mathrm{pH}>7)$, in order to produce methylol urea that dissolve in water. Microencapsulation process comprises two steps, i.e., emulsion process and microcapsule shell formation.

Materials: Urea was obtained as a fertilizer, which was recrystallized before used as a reagent. Formaldehyde was as $37 \%$ solution. The solution contains around $10 \%$ of methanol. Sodium hydroxide solution (around $1 \mathrm{~N}$ ) and citric acid solution (10\%) were employed to adjust the $\mathrm{pH}$ of solution. Palm oil was obtained as refined palm oil (frying vegetable oil), with its density $0.906 \mathrm{~g}$ $\mathrm{cm}^{-3}$ and its viscosity $28 \mathrm{cP}$ at room temperature.

\section{Methods:}

Pre-polymer preparation: One hundreds and twenty grams of recrystallized urea and $225 \mathrm{~mL}$ of $37 \%$ formaldehyde solution were charged into a three neck flask, equipped with mechanical stirrer, reflux condenser and water bath. The $\mathrm{pH}$ of solution was adjusted to $8-8.3$ by adding of $\mathrm{NaOH}$ solution. The solution was then heated to temperature of $70^{\circ} \mathrm{C}$. The reaction was run for $1 \mathrm{~h}$, while its temperature was maintained at $70^{\circ} \mathrm{C}$. At the end of the reaction, this urea-formaldehyde pre-polymer resin was cooled and diluted with distilled water to be $500 \mathrm{~mL}$ of UF resin solution. The resin concentration was $0.42 \mathrm{~g} \mathrm{~mL}^{-1}$.

Microencapsulation process: Microencapsulation process consists of 2 steps: Emulsion step and microcapsule shell formation step. In the emulsion step, UF resin was added with a certain amount of distilled water to make specified concentration of resin. Refined palm oil and UF resin solution were heated in water bath to $50-70^{\circ} \mathrm{C}$. As the temperature was reached, the mixture was stirred with ULTRA TURRAX homogenizer at the rotation speed of $15600 \mathrm{rpm}$ for 1050 min. White milky viscous liquid was produced. After homogenizing process, the homogenizer was replaced with a helical type stirrer. In the step of microcapsule shell formation, the stirring speed was maintained around $100 \mathrm{rpm}$, in order to keep homogeneous phase. Very low stirring speed could 
result in coalescence of oil bubble (which leads to phase separation), but high speed stirring would break up microcapsule shell formation. Citric acid solution was then added to the liquid mixture, to adjust its $\mathrm{pH}$ to 3. This process was run for 3-6 h, while its temperature was maintained constant. At the end of the process, the liquid mixture was cooled by addition of ice and cold distilled water. After one h of cooling, microcapsules product appeared as white solid. Some solid product floated at the top of liquid and the other settled at the bottom. These two solid products were filtered, washed with distilled water and then dried at $40^{\circ} \mathrm{C}$ under vacuum condition.

Dried top and bottom microcapsule products were weighed and analyzed its oil content. Certain amount of dried microcapsules was grounded and $\mathrm{N}$-hexane was added to extract the palm oil from ground microcapsules. The remaining ground solid was then filtered, dried in an oven at $100^{\circ} \mathrm{C}$ and finally weighed. The oil content can then be determined.

A sample of microcapsule product to be measured its diameter was prepared by attaching a thin layer of microcapsule paste on a microscope slide glass. The microcapsules image was captured by optical microscope provided with digital camera. The resulting image (picture) was interpreted using Image Pro Plus software, in which the diameter of around 100 or more microcapsule bubbles (in one picture) could be measured.

\section{RESULTS}

There were two parts of suspensions exist, after cooling the microcapsule product with ice and distilled water. The first was floating suspension as upper layer (top product) and the second was settling suspension (bottom product). Few experiments had only one layer product, either floating suspension or settling one at the bottom. This kind of product, however, was poor quality microcapsule particle. In the case of floating suspension product only, microcapsule was unstable, which was easy to break up and coalesce, due to soft shell of microcapsule. In the case of settling solid product only, the settling solid was apparently fine solid powder, not microcapsule.

The top product was mainly floating microcapsules with a density less than $1 \mathrm{~g} \mathrm{~cm}^{-3}$. The bottom product was settling solids, a mixture of microcapsules and fine solid powder (called as UF polymer micro particles). It seems that some UF polymer micro particles attach to microcapsule bubble. These UF polymer micro particles have irregular shape; sometimes they agglomerated. The density of UF polymer from microcapsule shell was measured and its value was around $1.29-1.38 \mathrm{~g} \mathrm{~cm}^{-3}$. Because microcapsule bubble was attached by several UF micro particles, the microcapsule bubble then settled down. Brown et al. (2003) also mentioned this phenomenon, where a number of micro particles attached to microcapsule shell.

The effect of temperature upon the characteristics of microcapsules is shown in Table 1 and Fig. 1. In this case, the efficiency of microencapsulation in Table 1 is defined as:

Oil efficiency $=\frac{\text { Weight of oil in microcapsule }}{\text { Initial weight of palm oil }}(100 \%)$

Resin eff. $=\frac{\text { Weight of resin in product }}{\text { Initial weight of resin in solution }}(100 \%)$

The experiments were conducted at $50-70^{\circ} \mathrm{C}, 30$ min of homogenization, $3 \mathrm{~h}$ of microencapsulation process and $\mathrm{pH}$ of 3 . UF pre-polymer solution $150 \mathrm{~mL}$ (concentration $0.294 \mathrm{~g} \mathrm{~mL}^{-1}$ ) was mixed with $42 \mathrm{~mL}$ of refined palm oil.

Table 2 provides the characteristics of microcapsule product and Fig. 2 shows the physical appearance of microcapsule produced at 10 and $20 \mathrm{~min}$ of homogenization time. During the emulsion step, homogenization time was varied from 10-50 min. The experiments were conducted at $50^{\circ} \mathrm{C}, 3 \mathrm{~h}$ of microencapsulation process and under $\mathrm{pH}$ of 3 .

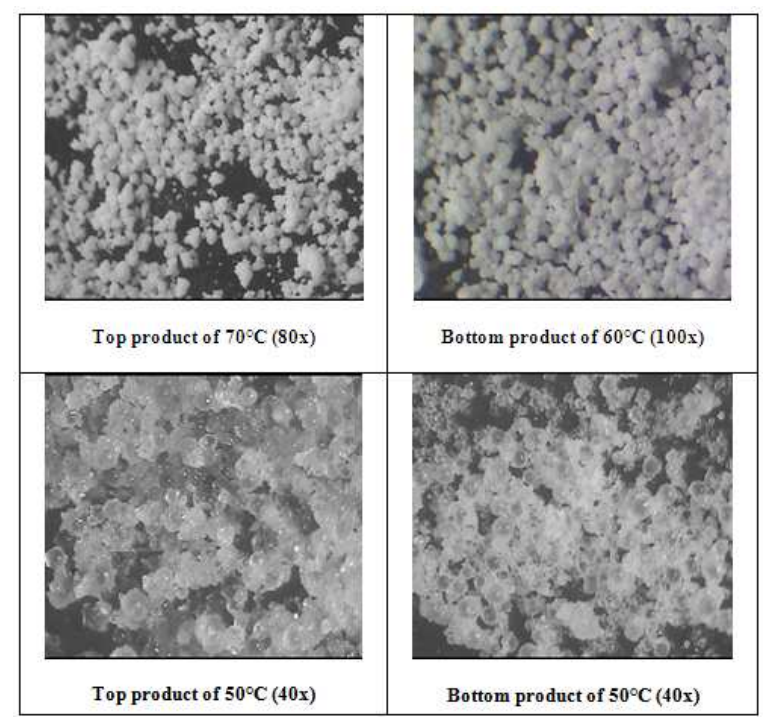

Fig. 1: Physical appearance of microcapsule produced at $50-70^{\circ} \mathrm{C}$ 
Am. J. Applied Sci., 7 (6): 739-745, 2010

Table 1: Characteristics of solid microcapsules produced at $50^{\circ}-70^{\circ} \mathrm{C}$

\begin{tabular}{|c|c|c|c|c|c|c|c|}
\hline \multirow{2}{*}{$\begin{array}{l}\text { Temperature } \\
\left({ }^{\circ} \mathrm{C}\right)\end{array}$} & \multicolumn{3}{|c|}{ Oil efficiency $(\%)$} & \multirow{2}{*}{$\begin{array}{l}\text { Resin eff. } \\
(\%)\end{array}$} & \multicolumn{2}{|c|}{ Oil content (weight fraction) } & \multirow{2}{*}{$\begin{array}{l}\text { Particle } \\
\text { shape }\end{array}$} \\
\hline & Top & Bottom & Total & & Top & Bottom & \\
\hline$\overline{70}$ & 5.31 & 8.43 & 13.74 & 49.24 & 0.381 & 0.148 & Irregular \\
\hline 60 & 9.61 & 10.11 & 19.72 & 50.32 & 0.508 & 0.171 & Irregular \\
\hline 50 & 36.48 & 40.14 & 76.62 & 47.62 & 0.661 & 0.524 & Spherical \\
\hline
\end{tabular}

Table 2: Characteristics of microcapsules, top and bottom products at various homogenization time

\begin{tabular}{|c|c|c|c|c|c|c|c|c|}
\hline \multirow[b]{2}{*}{$\begin{array}{l}\text { Time } \\
(\mathrm{min})\end{array}$} & \multicolumn{3}{|c|}{ Oil efficiency $(\%)$} & \multirow[b]{2}{*}{$\begin{array}{l}\text { Resin eff. } \\
(\%)\end{array}$} & \multicolumn{2}{|c|}{ Oil content (wt. fraction) } & \multirow[b]{2}{*}{$\begin{array}{l}\text { Shell thickness } \\
(\mu \mathrm{m})\end{array}$} & \multirow[b]{2}{*}{$\begin{array}{l}\mathrm{D}_{\mathrm{avg}} \\
(\mu \mathrm{m})\end{array}$} \\
\hline & $\begin{array}{l}----- \\
\text { Top }\end{array}$ & Bottom & Total & & $\begin{array}{l}\text { Top } \\
\text { To---- }\end{array}$ & Bottom & & \\
\hline 10 & 13.74 & 29.37 & 43.12 & 21.72 & 0.701 & 0.603 & 3.34 & 63.87 \\
\hline 20 & 24.04 & 56.66 & 80.69 & 43.70 & 0.675 & 0.592 & 3.16 & 51.37 \\
\hline 40 & 24.36 & 61.30 & 85.66 & 48.81 & 0.630 & 0.592 & 3.43 & 45.58 \\
\hline 50 & 28.22 & 56.42 & 84.64 & 49.95 & 0.621 & 0.581 & 4.09 & 49.97 \\
\hline
\end{tabular}

Table 3: Effect of the microencapsulation time upon the microcapsule characteristics

\begin{tabular}{|c|c|c|c|c|c|c|c|c|}
\hline \multirow[b]{2}{*}{ Time (h) } & \multicolumn{3}{|c|}{ Oil efficiency (\%) } & \multicolumn{5}{|c|}{ Oil content (wt. Fraction) } \\
\hline & Top & Bottom & Total & $(\%)$ & Top & $\begin{array}{l}\text { Resin Eft. } \\
\text { Bottom }\end{array}$ & $\begin{array}{l}\text { Shell thickness } \\
(\mu \mathrm{m})\end{array}$ & $\begin{array}{l}\mathbf{D}_{\text {avg }} \\
(\mu \mathrm{m})\end{array}$ \\
\hline 3 & 36.48 & 40.14 & 76.62 & 47.62 & 0.661 & 0.524 & 7.61 & 108.16 \\
\hline 4 & 39.86 & 43.74 & 83.59 & 46.83 & 0.679 & 0.553 & 5.22 & 66.12 \\
\hline 5 & 56.23 & 32.23 & 88.46 & 49.30 & 0.750 & 0.456 & 4.92 & 47.84 \\
\hline 6 & 59.31 & 25.27 & 84.58 & 53.82 & 0.776 & 0.359 & 4.25 & 70.99 \\
\hline
\end{tabular}

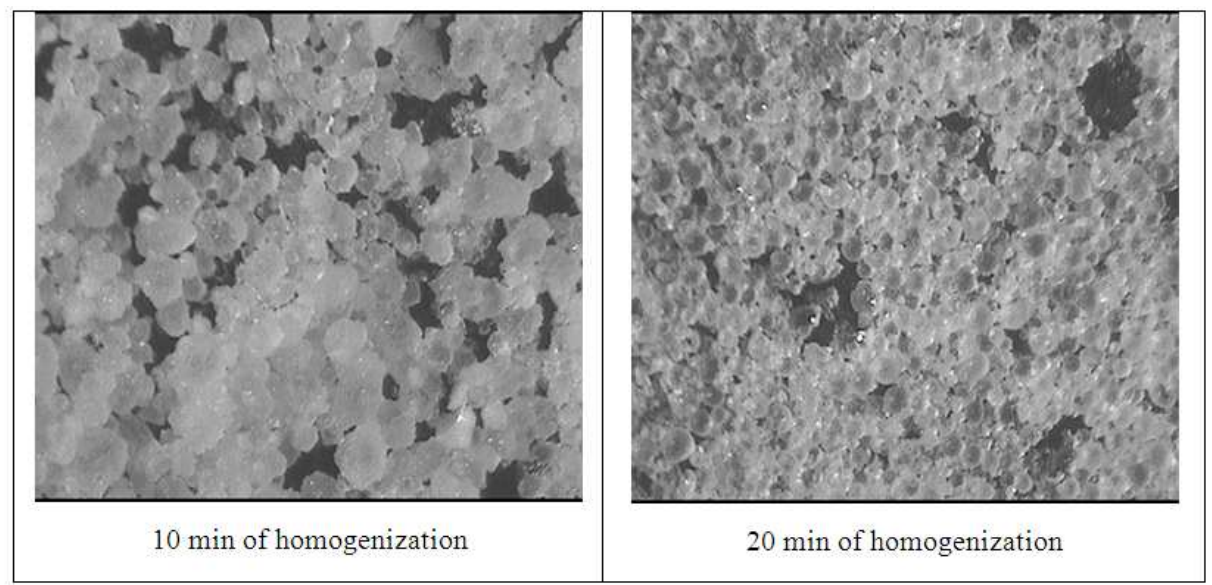

Fig. 2: Microcapsule appearance produced at 10 and $20 \mathrm{~min}$ of homogenization

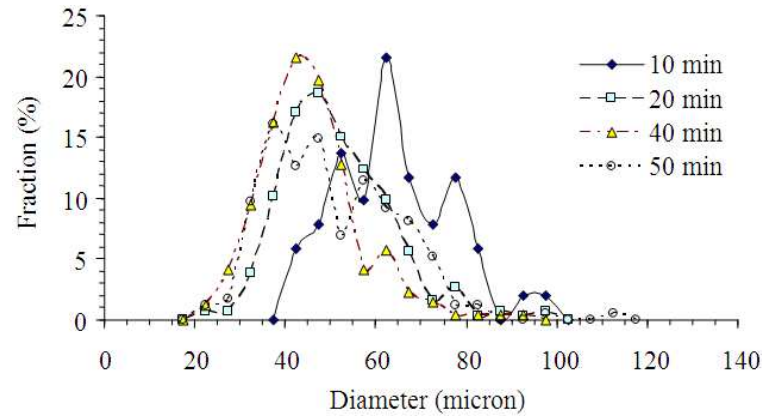

Fig. 3: Distribution of microcapsule diameter at 10 and 20 min of homogenization

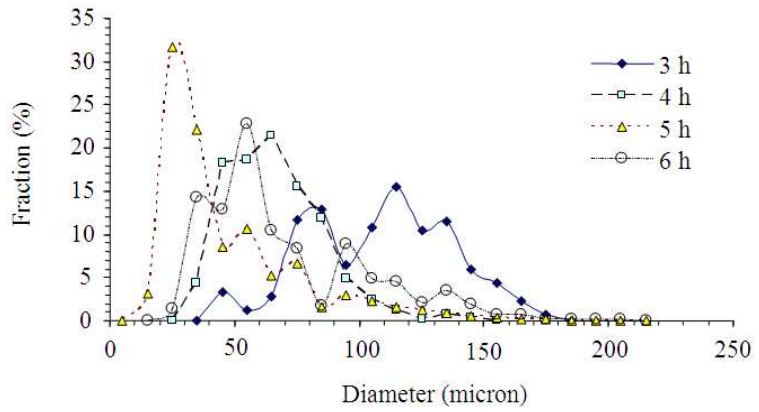

Fig. 4: Distribution of microcapsule diameter at several microencapsulation time 
Microencapsulation time was varied from 3-6 $\mathrm{h}$ in the second step of microencapsulation process. The experiments were conducted at $50^{\circ} \mathrm{C}, 30 \mathrm{~min}$ of homogenization, under $\mathrm{pH}$ of 3 , with pre-polymer solution $150 \mathrm{~mL}$ and refined palm oil $42 \mathrm{~mL}$. Table 3 provides the characteristics of top and bottom products.

Distribution of microcapsule diameter is shown in Fig. 3 and 4 for various homogenization and microencapsulation time.

\section{DISCUSSION}

The microcapsule product showed that besides microcapsule was formed, micro particle was also produced, as shown in Fig. 1. It can be concluded that during microencapsulation process, two simultaneous processes occurred: reaction of UF in the solution to produce UF micro particles and reaction of UF resin at the emulsion interface to form microcapsule shell. The mechanism of microencapsulation process is proposed as follows. During the emulsion step, palm oil bubbles adsorb some amount of UF pre-polymer resin at the bubble interface. When the $\mathrm{pH}$ of pre-polymer solution was changed into acidic condition (in the microcapsule shell formation step), urea-formaldehyde condensation reaction took place at high rate, both in the solution (yielding UF micro particle) and at the emulsion interface (forming microcapsule shell). The overall UF reaction rate $R_{p}$ is then proposed as follows:

$\mathrm{R}_{\mathrm{p}}=\mathrm{k}_{\mathrm{r}} \cdot\left(\mathrm{C}_{\mathrm{UF}}\right)^{2}+\mathrm{k}_{\mathrm{c}} \mathrm{a}\left(\mathrm{C}_{\mathrm{UF}}-\mathrm{C}_{\mathrm{UF}, \mathrm{s}}\right)$

Where:

$\begin{array}{ll}\mathrm{k}_{\mathrm{r}} & =\text { The reaction rate constant } \\ \mathrm{k}_{\mathrm{c}} \mathrm{a} & =\text { The mass transfer coefficient } \\ \mathrm{C}_{\mathrm{UF}} & =\text { UF pre-polymer concentration in the } \\ & =\text { aqueous phase } \\ \mathrm{C}_{\mathrm{UF}, \mathrm{s}} & =\begin{array}{l}\text { UF pre-polymer concentration at the } \\ \text { microcapsule surface }\end{array} \\ \mathrm{k}_{\mathrm{r}} \cdot\left(\mathrm{C}_{\mathrm{UF}}\right)^{2} & =\begin{array}{l}\text { The rate of UF polymer micro } \\ \text { particles formation }\end{array} \\ \mathrm{k}_{\mathrm{c}} \mathrm{a}\left(\mathrm{C}_{\mathrm{UF}}-\mathrm{C}_{\mathrm{UF}, \mathrm{s}}\right)= & \begin{array}{l}\text { The rate of microcapsule shell } \\ \text { formation. }\end{array}\end{array}$

The rate of condensation reaction is high in acidic condition. In this experiment, microencapsulation process was carried out at low $\mathrm{pH}$, which could lead to solid UF polymer production. It was observed in the experiment of $\mathrm{pH}$ variation (from 2-5), microencapsulation process at lower $\mathrm{pH}$ produced higher amount of solid UF micro particles, compared to that at higher $\mathrm{pH}$. In this case, the reaction rate constant $\mathrm{k}_{\mathrm{r}}$ is proportional to the concentration of $\mathrm{H}^{+}$: high $\mathrm{H}^{+}$ concentration (low $\mathrm{pH}$ ) means high $\mathrm{k}_{\mathrm{r}}$. On the other hand, the mass transfer coefficient $k_{c}$ a is not influenced by $\mathrm{H}^{+}$concentration. Hence, the rate of UF micro particles formation at low $\mathrm{pH}$ can be higher than the rate of microcapsule shell formation, or the amount of solid UF micro particles is higher at low $\mathrm{pH}$.

Effect of temperature: Table 1 show that total oil efficiency of microencapsulation process of palm oil was $76.62 \%$ at $50^{\circ} \mathrm{C}$ and decreased to $13.74 \%$ at $70^{\circ} \mathrm{C}$. This means that the amount of oil encapsulated at $70^{\circ} \mathrm{C}$ is less than the amount of oil encapsulated at $50^{\circ} \mathrm{C}$. Meanwhile, the unencapsulated oil floated at the top of UF prepolymer solution. Resin efficiency remains constant (around $50 \%$ ) at $50-70^{\circ} \mathrm{C}$, or it is independent of temperature. This indicates that the amount of total solid UF polymer in the product (as micro particles and as microcapsule shell) is constant. This also means that the overall rate of UF reaction $R_{p}$ is constant. According to the theory, $\mathrm{k}_{\mathrm{r}} \cdot\left(\mathrm{C}_{\mathrm{UF}}\right)^{2}$ (micro particles formation) increases with the increase of temperature. Consequently, the increase of temperature causes the decrease of microcapsule shell formation (as shown by the second term in Eq. 3). This is in line with the trend of total oil efficiency, as shown in Table 1. It is also clearly shown in Fig. 1 that the top product of $70^{\circ} \mathrm{C}$ and the bottom product of $60^{\circ} \mathrm{C}$ is dominated by white UF micro particles, while microcapsules produced at $50^{\circ} \mathrm{C}$ (in the top and bottom product) contains less white UF micro particles.

Effect of homogenization time: Table 2 shows that total oil and resin efficiencies gradually rise as the homogenization time increases up to $40 \mathrm{~min}$ and then remain constant after $40 \mathrm{~min}$ (total oil efficiency around $85 \%$ and resin efficiency around $49 \%$ ). In this case, the amount of UF pre-polymer resin adsorbed at the emulsion interface increases as homogenization time increases, until the oil in emulsion is saturated with UF pre-polymer at around 30-40 min of homogenization. When the oil in emulsion is saturated with UF prepolymer resin, the resin efficiency is at maximum and it remains constant for longer homogenization time. On the other hand, the increase of resin efficiency reduces the oil content both at the top and bottom products, as also shown in Table 2. Although the increase is not prominent, longer homogenization time also causes thicker microcapsule shell (from $3.34 \mu \mathrm{m}$ at $10 \mathrm{~min}$ $4.09 \mu \mathrm{m}$ at $50 \mathrm{~min}$ ). Figure 2 shows the appearance of microcapsule produced at 10 and $20 \mathrm{~min}$ of homogenization time. It is clearly appeared that the quality of microcapsule produced at $10 \mathrm{~min}$ is poor and 
the microcapsule is apparently sticky, while microcapsule produced at 20 min shows good quality. It can be concluded that homogenization time is sufficient at 30-40 min. Average microcapsule diameter $D_{\text {avg }}$ also seems to be constant after 20 min of homogenization, i.e., around $50 \mu \mathrm{m}$.

Effect of microencapsulation time: Table 3 shows that the increase of microencapsulation time only slightly increases resin efficiency, from $47.62 \%$ at $3 \mathrm{~h}$ to $53.82 \%$ at $6 \mathrm{~h}$ for resin efficiency. This means that after $3 \mathrm{~h}$ of microencapsulation process, the overall rate of UF reaction $R_{p}$ is very low, or the amount of UF micro particles and microcapsule shells only slightly increase. It can be concluded that basically no more UF micro particles and microcapsule shells were formed.

However, oil efficiency and oil content at the top product show different trend with oil efficiency and oil content at the bottom. As the microencapsulation time rises, oil efficiency and oil content at the top product increases, but oil efficiency and oil content at the bottom product decreases. It seems that there is migration of small diameter microcapsules from the bottom product to the top product, which is probably caused by detachment of some micro particles from microcapsule surface due to turbulent action of stirrer. Because the stirring process takes place for a long time, some attaching micro particles at the microcapsule surface are gradually released, both at the top and bottom products. At the bottom product, small diameter microcapsule will rise to float at the top layer, after releasing some micro particles. On the other hand, some released micro particles at the top product will settle down to the bottom. This causes oil efficiency and oil content at the top product increases, while oil efficiency and oil content at the bottom product decreases. The microcapsule average diameter $D_{\text {avg }}$ shows the same trend with the top product, which decreases from 108 $\mu \mathrm{m}$ at $3 \mathrm{~h}$-around $70 \mu \mathrm{m}$ at $6 \mathrm{~h}$. This phenomenon may be caused by breaking-up of some big microcapsule bubbles into smaller diameter microcapsules due to the effect of extended stirring time. This is also followed by reduction of microcapsule shell thickness, from $7.61 \mu \mathrm{m}$ at $3 \mathrm{~h}$ to $4.25 \mu \mathrm{m}$ at $6 \mathrm{~h}$. Although the stirring speed is low (around $100 \mathrm{rpm}$ ), the shearing force of stirring is likely to influence the microcapsule shell strength. Apart from the microcapsule size, it can be concluded that $3 \mathrm{~h}$ of microencapsulation process is sufficient to produce a good quality microcapsule.

Distribution of microcapsule diameter: Figure 3 and 4 show the distribution of microcapsule diameter at various homogenization and microencapsulation time. The distribution of microcapsule diameter in both Fig. 3 and 4 has the same trend that the size distribution is dominated by smaller diameter or it is skew distribution, not Gaussian distribution. This may be due to the characteristics of homogenization process, where some small emulsion bubbles coalesce to form large bubbles as soon as emulsion bubbles exit from the homogenizer.

The microcapsule diameter distribution also shifts to smaller diameter as the homogenization and microencapsulation time increases, as also shown by the decrease of average diameter $\mathrm{D}_{\mathrm{avg}}$. It seems that equilibrium between turbulent force and interfacial tension will be reached at a long time, because the distribution of microcapsule diameter and average diameter $\mathrm{D}_{\mathrm{avg}}$ tend to be constant as the homogenization and microencapsulation time increases. Based on the diameter distribution, microcapsule diameter generally ranges from $20 \mu \mathrm{m}$ to almost $220 \mu \mathrm{m}$.

\section{CONCLUSION}

Based on the experimental results, it is concluded that UF polymerization reaction takes place simultaneously in the solution and at the microcapsule surface. UF reaction in the solution produces UF polymer micro particles, while UF reaction at the microcapsule surface forms microcapsule shell. The UF polymer micro particles precipitate in the form of fine powder, attach to the microcapsule surface.

Higher microencapsulation temperature reduces the amount of microcapsule product and increase the amount of micro particles. The microcapsule diameter distribution shifts to smaller diameter and average diameter $\mathrm{D}_{\mathrm{avg}}$ tends to decrease as the homogenization and microencapsulation time increase. Microcapsule diameter ranges from $20 \mu \mathrm{m}$-around $220 \mu \mathrm{m}$. Based on oil and resin efficiencies as well as microcapsule characteristics, the process is best conducted at $50^{\circ} \mathrm{C}$, $30 \mathrm{~min}$ of homogenization and $3 \mathrm{~h}$ of microencapsulation time.

\section{ACKNOWLEDGEMENT}

The researchers are grateful to Gadjah Mada University, in supporting this research activity through fundamental research grant scheme and WCRU project.

\section{REFERENCES}

Antipov, A.A. and G.B. Sukhorukov, 2004. Polyelectrolyte multilayer capsules as vehicles with tunable permeability. Adv. Colloids Interface Sci., 111: 49-61. DOI: 10.1016/ j.cis.2004.07.006 
Brown, E.N., M.R. Kessler, N.R. Sottos and S.R. White, 2003. In situ poly(urea-formaldehyde) microencapsulation of dicyclopentadiene. J. Microencapsul., 20: 719-730. DOI: 10.1080/0265204031000154160

Deyrail, Y., N. Zydowicz and P. Cassagnau, 2004. Polymer crosslinking controlled by release of catalyst encapsulated in polycarbonate microspheres. Polymer, 45: 6123-6131. DOI: 10.1016/j.polymer.2004.06.064

Mayya, K.S., A. Bhattacharyya and J.F. Argillier, 2003. Microencapsulation by complex coacervation: Influence of surfactant. Polymer Int., 52: 644-647. DOI: 10.1002/pi.1125

Radtchenko, I.L., G.B. Sukhorukov and H. Möhwald, 2002. Incorporation of macromolecules into polyelectrolyte micro and nanocapsules via surface controlled precipitation on colloidal particles. Colloids Surfaces A. Physicochem. Eng. Aspects, 202: 127-133.

Salaun, F. and I. Vroman, 2008. Influence of core materials on thermal properties of melamineformaldehyde microcapsules. Eur. Polymer J., 44: 849-860. 10.1016/j.eurpolymj.2007.11.018
Sukhorukov, G.B., A. Fery and H. Möhwald, 2005. Intelligent micro-and nanocapsules. Prog. Polymer Sci., 30: 885-897. DOI: 10.1016/j.progpolymsci.2005.06.008

Sun, G. and Z. Zhang, 2002. Mechanical strength of microcapsules made of different wall materials. Int. J. Pharm., 242: 307-311.

Yang, C.C. and I.H. Pan, 1996. Preparation of pesticide microcapsule. US Patent 5576008. http://www.freepatentsonline.com/5576008.html

Yin, T., M.Z. Rong, M.Q. Zhang and G.C. Yang, 2007. Self-healing epoxy composites-preparation and effect of the healant consisting of microencapsulated epoxy and latent curing agent. Comp. Sci. Technol., 67: 201-212. DOI: 10.1016/j.compscitech.2006.07.028 